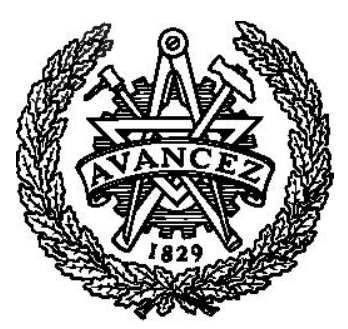

CHALMERS

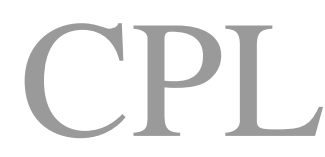

Chalmers Publication Library

Institutional Repository of Chalmers University of Technology

http://publications. lib.chalmers. se

This is an author produced version of a paper published in Energy Policy.

This paper has been peer-reviewed but does not include the final publisher proof-corrections or journal pagination.

Citation for the published paper:

Elin Svensson, Thore Berntsson and Ann-Brith Strömberg

Benefits of using an optimization methodology for identifying robust process integration investments under uncertainty - A pulp mill example

Energy Policy, 2009, Vol. 37, Issue 3: pp 813-824

URL: http://dx.doi.org/10.1016/j .enpol . 2008 . 10.024

Access to the published version may require subscription. Published with permission from:

Elsevier 


\title{
Benefits of using an optimization methodology for identifying robust process integration investments under uncertainty - A pulp mill example
}

\author{
Elin Svensson ${ }^{\mathrm{a},}{ }^{*}$, Thore Berntsson ${ }^{\mathrm{a}}$, Ann-Brith Strömberg ${ }^{\mathrm{b}}$ \\ ${ }^{a}$ Heat and Power Technology Group, Department of Energy and Environment, Chalmers University of \\ Technology, SE-412 96 Göteborg, Sweden. \\ ${ }^{b}$ Fraunhofer-Chalmers Research Centre for Industrial Mathematics, Chalmers Science Park, SE-412 88 \\ Gothenburg, Sweden. Presently at Department of Mathematical Sciences, Chalmers University of \\ Technology and Department of Mathematical Sciences, University of Gothenburg, SE-412 96 Göteborg,
} Sweden.

\begin{abstract}
This paper presents a case study on the optimization of process integration investments in a pulp mill considering uncertainties in future electricity and biofuel prices and $\mathrm{CO}_{2}$ emissions charges. The work follows the methodology described in Svensson, E. et al. (2008b) where a scenario-based approach is proposed for the modelling of uncertainties. The results show that the proposed methodology provides a way to handle the timedependence and the uncertainties of the parameters. For the analyzed case, a robust solution is found which turns out to be a combination of two opposing investment strategies. The difference between short-term and strategic views for the investment decision is analyzed and it is found that uncertainties are increasingly important to account for as a more strategic view is employed. Furthermore, the results imply that the obvious effect of policy instruments aimed at decreasing $\mathrm{CO}_{2}$ emissions is, in applications like this, an increased profitability for all energy efficiency investments, and not as much a shift between different alternatives.
\end{abstract}

Keywords: process integration, stochastic programming, investment planning.

\section{Introduction}

Uncertainties in future market conditions affect the decisions on investments in process integration measures for increased energy efficiency. Investment alternatives that would be profitable might not be realized without a well-founded method to model the uncertainties. Therefore, we have developed a methodology to optimize process integration investments under uncertainty (Svensson, E. et al., 2008b). The methodology provides a five-step procedure for carrying out this optimization.

In order to demonstrate the use of the proposed methodology, a case study from the pulp and paper industry has been carried out and the work and results are presented here. This sector, with its global consumption of 6.5 EJ of final energy in 2004, was the fourth largest industrial consumer of energy, and has the potential to increase its energy efficiency enough to make the industry a net supplier of clean energy from biomass in the future (IEA, 2007). Better heat integration, larger mills, new drying technologies, black liquor gasifiers, and carbon capture and storage are all examples of improvements that will make this industry play an important role in the reduction of greenhouse gases in the future (Gielen and Taylor, 2007).

\footnotetext{
* Corresponding author. Tel.: +46 3177230 16; fax: + 4631821928.

E-mail address: el i n. svensson@hal mer s. se (Elin Svensson)
} 
In the U.S. pulp and paper sector a cost-effective primary energy savings potential of $16 \%$ has been identified (Martin et al., 2000). Also in Sweden, the potential for $\mathrm{CO}_{2}$ reductions in pulp and paper mills has been found to be large, and in many cases possible to realize even at a negative cost (Möllersten et al., 2003; Axelsson and Berntsson, 2008). However, in these studies, the cost of $\mathrm{CO}_{2}$ reduction varied substantially depending on the assumptions about, for example, the electricity prices and production technologies. These involve uncertainties which were handled using sensitivity analysis. For the pulp and paper industry, the approach of sensitivity analysis has also been used in a study on the possibilities for investments in the chemical recovery cycle at a board mill (Karlsson and Söderström, 2002). By applying the methodology illustrated in this paper, the uncertainties are incorporated in the optimization at an earlier stage and not only in a post-optimization analysis

This case study deals with the investment decisions for a kraft pulp model mill that is faced with a planned production capacity increase. The conventional approach to enabling a production increase is to upgrade the recovery boiler, which is often one of the bottlenecks. There are, however, alternatives, especially if steam savings through process integration are also considered. The aim of this article is to illustrate, with the case study as an example, the benefit of using the above-mentioned methodology for incorporating uncertainties in the analysis of process integration investments. The investment analysis will provide a basis for decisions concerning different approaches to increase the capacity, but also to what extent process integration should be carried out in combination with the other measures that have to be taken.

\section{Methodology}

In a previous paper (Svensson, E. et al., 2008b), a five-step methodology was presented for the optimization of energy efficiency investments under uncertainty. The proposed methodology enables the optimization of investments with respect to their net present value, and uncertainties in future energy prices and policies are explicitly incorporated in a model for optimization under uncertainty (a stochastic programming model). As a result of the optimization approach, complex investment alternatives, allowing for combinations of energy efficiency measures, can be analyzed. According to Svensson, E. et al. (2008b), the main steps of the methodology are:

1. Identify the opportunities for energy efficiency investments.

2. Define the constraints on and effects of combining measures.

3. Gather and compute input data.

4. Develop a scenario model.

5. Solve the model and analyze the results.

The optimization model is assumed to be a multistage mixed-binary linear stochastic programming model. The binary variables typically denote whether investments are made or not (linearity is preferred to make the model easier to solve, but is not a requirement if a suitable solver for nonlinear mixed-integer models is available). It is assumed that investment decisions are made before uncertainties are resolved and any price changes occur. Additional investment may be carried out later, before any further price changes occur. Uncertain parameters, such as energy prices and policy instruments, are modelled using a scenario-based approach. The solution to the optimization model will be an optimal investment plan with respect to the NPV on the basis of the information we have 
about the future today. A paper presenting a detailed description of the mathematical model is under preparation (Svensson, E. et al., 2008a).

Although we have modelled the investment problem under uncertainty as a multistage stochastic programming model and not explicitly used the concept of real options (see e.g. Dixit and Pindyck, 1994), there is no fundamental between these two approaches. The theory of real options can be used to explain, in economic terms, the effect of accounting for uncertainties in investment decision-making Multistage stochastic programming is essentially one way to model the real options problem, while real options theory provides a framework for a better understanding of stochastic programming (Christiansen and Wallace, 1998).

\section{Case study}

\subsection{General description of the case}

The case study has been chosen to show what kind of data is needed, how to include specific constraints, and how to analyze the results from using the proposed methodology (Svensson, E. et al., 2008b). Suggestions for process integration measures are taken from a previous study on heat integration opportunities in average Scandinavian kraft pulp mills, using pinch analysis on model mills (Axelsson et al., 2006a). Process data for this case study are taken from that study and from a study comparing lignin extraction and power production (Olsson et al., 2006). However, the work presented here is mainly based on another study by Axelsson et al. (2006b), which investigates the possibility of making steam savings and extracting lignin as an alternative to upgrading the recovery boiler in the case of a planned production increase by $25 \%$ at a kraft pulp mill. The mills studied in the above-mentioned papers are computer models of kraft pulp mills typical for Scandinavia today. Two mills were studied, one with a high water usage and one with a low water usage. For this case study, we picked one of them, the high-water-usage mill. The pulp mill is today self-sufficient in energy supply from the wood raw-material. No external fuel is imported, and hence, all energy supply to the mill is based on biomass.

The capacity increase necessitates either the investment in a new recovery boiler and evaporation plant (see Figure 1), or the separation of enough lignin from the black liquor in order not to overload the boiler (see Figure 2). To be able to increase the production by $25 \%$ without exceeding the capacity of the existing recovery boiler, lignin has to be extracted from the black liquor in the evaporation plant. Figure 3 illustrates how the lignin separation process is integrated with the evaporation plant. At least 0.15 tonnes/ $\mathrm{ADt}^{1}$ has to be separated from the black liquor (FRAM, 2005).

\footnotetext{
${ }^{1} \mathrm{ADt}=$ Air-Dried (metric) Tonnes (of pulp).
} 


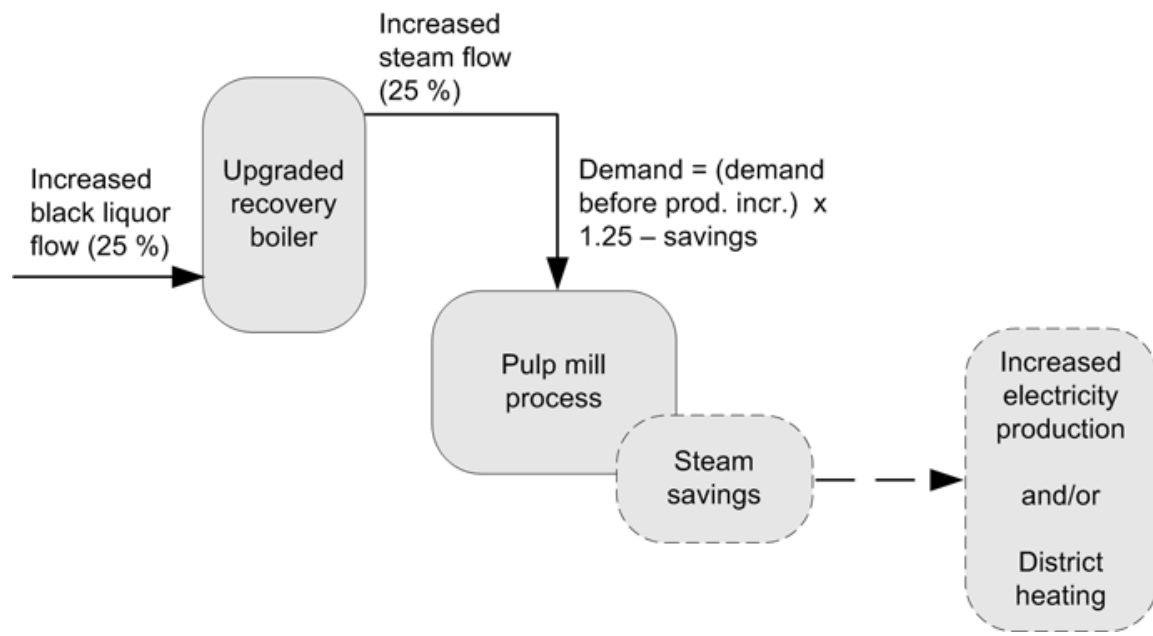

Figure 1: The approach of upgrading the recovery boiler to handle the production increase. Without steam savings, the increased steam demand will equal the increased output from the new boiler. Steam savings yield a steam surplus which can be used for electricity production or district heating.

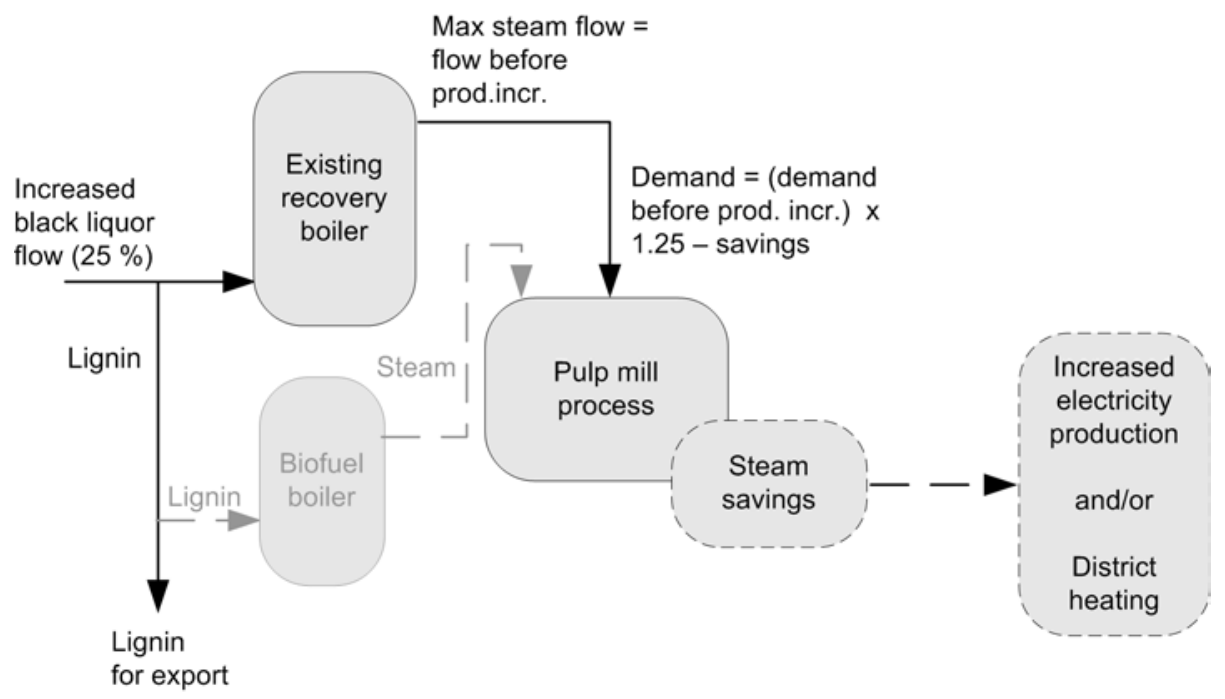

Figure 2: The approach of lignin separation to handle the production increase. Without steam savings, the lignin has to be used internally to cover the increased steam demand of the process. With enough steam savings the lignin can be exported. Further steam savings result in a steam surplus that can be used for electricity production or district heating.

If enough steam savings are achieved, the separated lignin is not needed at the mill, which means that the lignin can be exported for use as biofuel. A consequence of exporting the lignin is that the possibility for electricity production is decreased since less high-pressure steam is produced. In this case study, internal use of the extracted lignin for additional production of high-pressure steam is not considered, assuming that there is no suitable biofuel boiler available at the mill. Hence, steam savings have to be carried out, at least by an amount corresponding to the increased steam demand due to the capacity increase. 


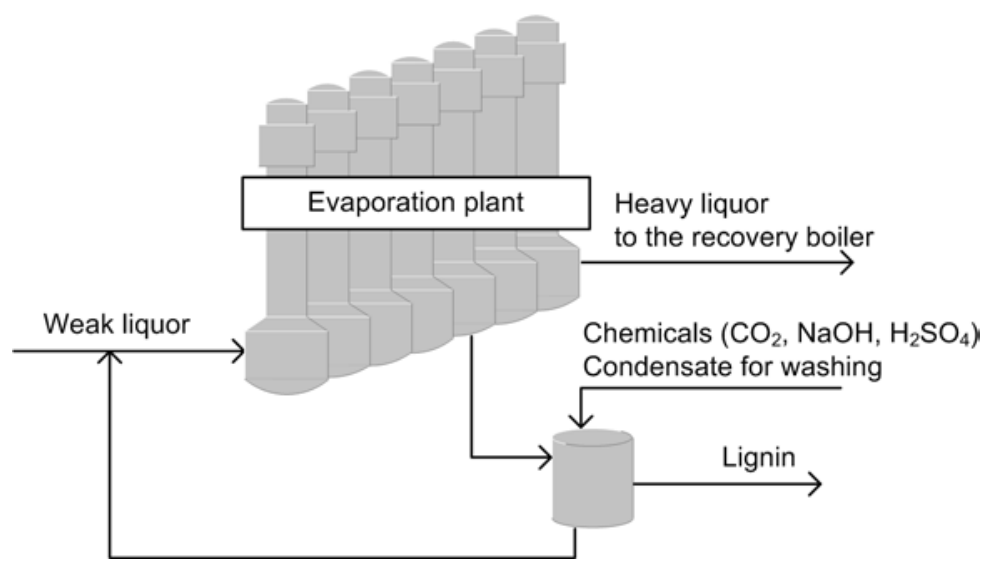

Figure 3: Lignin is separated from a black liquor stream that is diverted from the evaporation plant. The remaining black liquor is recirculated to the evaporation plant together with the added water and chemicals.

The main focus of this work is on the incorporation of uncertainties in the investment optimization, rather than the process integration analysis that the optimization model is based on. We assume familiarity with the pulp industry for understanding the underlying assumptions regarding the plant and the possibilities for energy savings. Enough details are provided for those who know the process well to get a complete description of the case. The interested reader is referred to the above-mentioned original papers on the possibilities for process integration in the kraft pulp mill for more details regarding input data and assumptions and for a description of the model mill.

All input data used in this paper are taken from the case studies mentioned above, except for data concerning district heating, which are taken from a study of the potential for using excess heat from kraft pulp mills for district heating in Sweden (Svensson, I.-L. et al., 2008c). In that study, the method MIND (Karlsson and Sandberg, 2004) was used for optimization. MIND is a method for modelling of industrial energy systems, so far without the possibility of incorporating uncertainties explicitly in the optimization model.

By using process integration techniques and methods such as pinch analysis (Kemp, 2007; Smith, 1995), a number of different opportunities to create a steam surplus at the mill can be identified and the amount of available excess heat can be determined. Excess heat refers to heat from the process that is not utilized today and thus is available for internal or external use. Such excess heat may be of many qualities, for example steam or hot water. As mentioned, the steam surplus can be used either in combination with lignin extraction to avoid upgrading the recovery boiler, or to increase the electricity production. High- and/or medium-pressure steam surplus can be passed through a back-pressure turbine to produce electricity, either if the existing turbines have extra capacity, or if new turbines are installed. In the model mill, which is the basis for the studies by Axelsson et al. (2006b), the back-pressure turbine does not accommodate all steam even at present conditions. Instead, some steam is passed through letdown valves to lower pressures. The low-pressure steam surplus is then available for use in a condensing turbine. Finally, we also added the possibility to use excess heat or low-pressure steam for district heating in our analysis.

In the following subsections we present the implementation of the five-step methodology for the pulp mill case study. 


\subsection{Step 1 - Identify the opportunities for energy efficiency investments}

The opportunities for energy efficiency investments are identified using process integration methods, in this case pinch analysis. The identified measures are listed with their corresponding investment costs and resulting energy savings in Table 1. Here, the different measures result in savings of low-pressure (LP), medium-pressure (MP) and/or high-pressure (HP) steam. In total without any savings, the steam demand of the process after the production increase will be $238 \mathrm{t} / \mathrm{h}$ LP steam, and $86 \mathrm{t} / \mathrm{h}$ MP steam. The maximum net production of HP steam for the existing recovery boiler is $243 \mathrm{t} / \mathrm{h}$.

Table 1: Energy-saving measures according to Axelsson et al. (2006a; 2006b).

\begin{tabular}{|c|c|c|c|c|c|}
\hline \multirow[t]{2}{*}{$\begin{array}{l}\text { Energy-saving } \\
\text { measure }\end{array}$} & \multirow[t]{2}{*}{ Description } & \multirow[t]{2}{*}{$\begin{array}{c}\text { Inv. Cost } \\
{[\mathrm{M} €]}\end{array}$} & \multicolumn{3}{|c|}{$\begin{array}{c}\text { Steam savings } \\
{[\mathrm{t} / \mathrm{h}]}\end{array}$} \\
\hline & & & $\mathbf{L P}$ & MP & HP \\
\hline $\begin{array}{l}\text { New 3-stage } \\
\text { flash }\end{array}$ & $\begin{array}{l}\text { A new 3-stage flash system } \\
\text { is introduced with which } \\
\text { heat from the black liquor } \\
\text { replaces live steam in the } \\
\text { chip steaming and digester }\end{array}$ & 3.5 & 3.1 & 16.1 & 0 \\
\hline New HWWS & $\begin{array}{l}\text { A rebuilt hot and warm } \\
\text { water system (HWWS) with } \\
\text { a small driving temperature } \\
\text { difference }(\Delta \mathrm{T}) \text { and avoided } \\
\text { imbalances }\end{array}$ & 0.6 & 12.5 & 0 & 0 \\
\hline Wood yard & $\begin{array}{l}\text { Rebuilding of the wood yard } \\
\text { to make use of a warm } \\
\text { effluent instead of LP steam } \\
\text { for heating }\end{array}$ & 0 & 2.6 & 0 & 0 \\
\hline Shoe press & $\begin{array}{l}\text { A mechanical shoe press is } \\
\text { installed for drying the pulp, } \\
\text { decreasing the need for LP } \\
\text { steam in the thermal dryer }\end{array}$ & 6.0 & 11.8 & 0 & 0 \\
\hline Blow out & $\begin{array}{l}\text { Make use of the LP steam } \\
\text { that today is blown into the } \\
\text { atmosphere }\end{array}$ & 0 & 13.9 & 0 & 0 \\
\hline Blow down & $\begin{array}{l}\text { Avoid passing steam } \\
\text { through letdown valves }\end{array}$ & 0 & -78.4 & -39.5 & 102.5 \\
\hline
\end{tabular}


Table 1 (continued)

\begin{tabular}{|c|c|c|c|c|c|}
\hline $\begin{array}{l}\text { Energy-saving } \\
\text { measure }\end{array}$ & Description & $\begin{array}{l}\text { Inv. Cost } \\
\text { [M€] }\end{array}$ & \multicolumn{3}{|c|}{$\begin{array}{c}\text { Steam savings } \\
{[\mathrm{t} / \mathrm{h}]}\end{array}$} \\
\hline Convap ${ }^{a} /{ }^{b}+D S$ & $\begin{array}{l}\text { A new modern 7-effect } \\
\text { evaporation plant with } \\
\text { integrated stripper, also } \\
\text { increasing the dry solids } \\
\text { (DS) content of the black } \\
\text { liquor (from } 73 \% \text { to } 80 \% \text { ) }\end{array}$ & $\begin{array}{l}{ }^{\mathrm{a}} 9.3 \\
\mathrm{~b} 9.7\end{array}$ & 59.5 & -19.3 & 9.3 \\
\hline $\operatorname{PIvap}^{\mathrm{a}} /^{\mathrm{b}}+\mathrm{DS}$ & $\begin{array}{l}\text { A new process integrated 7- } \\
\text { effect evaporation plant and } \\
\text { increased dry solids (DS) } \\
\text { content }\end{array}$ & $\begin{array}{l}{ }^{\mathrm{a}} 11.7 \\
\mathrm{~b} 10.3\end{array}$ & 63.9 & -14.3 & 9.3 \\
\hline
\end{tabular}

Additionally and naturally, the recovery boiler upgrade (RBU) and the simple evaporation plant with increased capacity have to be included as possible investments although they are not actually improving the energy efficiency of the plant. These two investments, presented in Table 2, do not result in any steam savings, but are included in the optimization model as one of the required alternative approaches to a production increase. In the model they are treated analogously as the energy-saving measures, but with the resulting steam savings equal to zero.

Table 2: Investments required for the traditional approach to increase the production.

\begin{tabular}{lll}
\hline Measure & Description & Inv. cost [M€] \\
\hline RBU & $\begin{array}{l}\text { Recovery boiler upgrade, including new } \\
\text { cooling equipment. }\end{array}$ & 29.8 \\
\hline Evap & $\begin{array}{l}\text { A least-cost new evaporation plant } \\
\text { adapted for the increase in production, } \\
\text { but not for lignin separation. }\end{array}$ & 4.4 \\
\hline
\end{tabular}

Furthermore, the process integration analysis identifies 16.2 MW excess heat of about $100^{\circ} \mathrm{C}$ that will be available for district heating after the production increase, provided that it is not used for other process integration purposes. About 53.8 MW excess heat of lower temperature $\left(\sim 60^{\circ} \mathrm{C}\right)$ is also available, but it needs to be heat-pumped to an adequate temperature for district heating.

Table 3 lists the possible different ways of utilizing the identified energy surplus at the mill. Each of these measures will result in the production of either lignin, electricity, or heat that can be exported to provide an income, and thereby motivate the investment costs that will be decided on. The production and revenues are modelled as functions of the installed production capacity, the implemented steam savings, and the price levels.

Table 3: Measures for utilization of the energy surplus to enable energy exports.

\begin{tabular}{ll}
\hline Energy export measure & Description \\
\hline Lignin & Lignin separation \\
BP turb & Back-pressure turbine power generation \\
\hline
\end{tabular}




\begin{tabular}{ll}
\hline Cond. turb & Condensing turbine power generation \\
DH LP & DH (District Heating) from low-pressure steam \\
DH 100 & DH from medium quality $\left(100^{\circ} \mathrm{C}\right)$ excess heat \\
DH 60 & DH from low quality $\left(60^{\circ} \mathrm{C}\right)$ excess heat (heat pumped) \\
\hline
\end{tabular}

\subsection{Step 2 - Define the constraints on and effects of combining measures}

As can be seen in Table 1, the potential steam saving for a single measure varies a lot. If all opportunities could be realized, the steam saving would be substantial. However, this is not the case. Some measures can be combined, while others can only be combined to a certain extent or under certain restrictions; some measures cannot be combined at all.

In accordance with the discussion in Section 3.1 describing the general assumptions for the case study, there are two main approaches to deal with the production increase: a recovery boiler upgrade, or lignin extraction (see Figures 1 and 2). Both of these approaches can be combined with energy savings to varying extent. If the recovery boiler is upgraded, there is no requirement to save steam; but if steam savings are carried out, it will render a steam surplus that, for example, can be used for electricity production. For lignin extraction, on the other hand, it is necessary to carry out steam savings. There is a lower limit on the steam savings, which is at least the amount corresponding to the increased process steam demand. However, it is not necessary to calculate this limit manually in advance. All of the constraints relating steam savings to, for example, the lignin extraction and the steam production in the recovery boiler are dealt with by generally formulated steam and mass balance constraints in the optimization model. Hence, these kinds of constraints do not have to be formulated explicitly for each case study, which is one of the strengths of the proposed optimization approach.

Besides the steam and mass balance constraints, there are additional constraints, due to technical limitations and requirements, that have to be formulated for each specific case. Furthermore, in this case study, there is a need to formulate the fact that some investments have to be carried out immediately because of the production increase, which is assumed to be realized in the beginning of the analyzed time period. The case-specific constraints are described below.

For the production increase, the most important constraint is that either the recovery boiler has to be upgraded (RBU) or lignin has to be separated. This investment has to be made immediately. Furthermore, the only opportunity to invest in RBU is from the start. Later on, this opportunity is foregone due to the long production downtime. If RBU is not carried out, at least 53.6 MW of lignin (corresponding to 0.15 tonnes/ADt) must be separated. A new evaporation plant is also necessary due to the production increase. The investment has to be made immediately.

A couple of constraint concern which steam-saving opportunities cannot be combined and which has to be combined. Only one new evaporation plant can be installed, either the cheapest one with no actual steam savings (Evap), or a more modern but conventional evaporation plant (Convap), or a process-integrated evaporation plant (PIvap). The new 3-stage flash cannot be combined with process-integrated evaporation (PIvap), but the hot and warm water system (HWWS) has to be rebuilt in order to install PIvap.

Constraints modelling the requirements on lignin separation state that lignin separation cannot be made without building a new evaporation plant, which then has to be adapted for lignin extraction. If the evaporation plant is in fact designed for lignin extraction, lignin has to be extracted by an amount that equals the design capacity of the 
evaporation plant. This is because the evaporation plant that is designed for lignin extraction is designed for different flows than those of a conventional evaporation plant.

For electricity production, the only constraint is that for an existing back-pressure turbine, the load cannot change independently for the high- and medium-pressure parts, but the steam flow change has to be equal for both parts. If the turbine is replaced by a new one, the steam flow can change freely.

A number of constraints limit the potential for district heating. If excess heat is used for process-integrated evaporation it is not available for district heating, i.e., PIvap cannot be combined with district heating production unless LP steam is the heat source for the district heating. In addition, the use of excess heat of $100^{\circ} \mathrm{C}$ for district heating (DH 100) cannot be combined with the new three-stage flash, for which most of that excess heat is used. Investments in district heating are assumed to be taken partially by the energy company. Thus, once district heating is decided on, the load is not allowed to decrease. Finally, the district heating load is limited by a demand curve (see Figure 4).

Many of the constraints in this case study arise because the amount of excess heat of low and medium quality is limited. Here, this is dealt with by adding constraints on measures that use excess heat. Another approach would have been to model excess heat as a fourth level of energy surplus in addition to LP, MP, and HP steam.

Care must be taken when formulating these constraints mathematically, especially when there is an aspect of time. The constraint that the HWWS must be rebuilt in order to istall PIvap may serve as an example. PIvap cannot be built without rebuilding the HWWS, but the opposite is definitely possible.

The constraint concerning the lignin extraction capacity of the evaporation plant is an example of the complexity of the constraints. In this case it is not only the time aspect, but also the demanded linearity of the model that makes the modelling a complex task (see Section 2, Methodology). Additional variables representing the lignin extraction capacity for the evaporation plant have to be introduced. The evaporation plant extraction capacity should be fixed except for when the evaporation plant is rebuilt. This implies that a multiplication of the lignin capacity variable and the investment decision variable is required. Avoiding the multiplication of variables requires multiple constraints if the same behaviour is to be expressed using linear functions.

\subsection{Step 3 - Gather and compute input data}

The necessary input to the model can be divided into four main groups: energy conversion data, investment and other cost functions, economic parameters such as the discount rate and economic lifetime, and finally prices. Prices constitute the stochastic part of the model and will be presented in Section 3.5.

In this case study, the basis for energy savings consists of steam at different pressure levels. Steam can be passed from higher to lower pressures through letdown valves. Quench water, i.e., water that is added to prevent the steam from being superheated, is then needed. Quench water is also needed for steam that is passed to the back-pressure turbine. A parameter relating the output steam flow from the valve or turbine, including the quench water, to the input steam flow is incorporated in the model to account for this. This parameter is easily calculated from the enthalpies of steam and water.

The parameters stating how much lignin, electricity, or heat can be obtained from a certain steam surplus are calculated based on a number of assumptions and simplifications. 
One simplification regards lignin extraction. When lignin is extracted, the steam demand of the evaporation plant becomes slightly higher than if no lignin were extracted. This means that the steam surplus actually becomes somewhat reduced. In the model, this is regarded as a lignin extraction efficiency, which is estimated to be $96 \%$. For an exact calculation of this efficiency that depends non-linearly on the lignin extraction rate, an iterative procedure would be required in which one step involves the design and operating optimization of the evaporation plant.

Regarding electricity production, the isentropic efficiency of a new back-pressure turbine is assumed to be higher than that of the old turbine. This should, for the old and new turbine, yield different values for how much electricity can be produced from a certain steam flow. For simplicity, the old and the new turbine are, however, modelled with the same value used as input. The isentropic efficiency for the new turbine is the one that is used which results in slight overestimation of the lost production in case of lignin extraction. In the case of increased electricity production, a new turbine is of course a necessity, and the assumed value of the isentropic efficiency will be correct. For the condensing turbine, the electricity output as a function of the steam input has been calculated from the assumption that the new back-pressure turbine is installed. If this assumption does not hold, the difference is mainly that the steam enthalpy at the condensing turbine inlet is changed, which would give an underestimation of the power output of approximately 4\%, according to our estimations.

Furthermore, the part-load conditions for the turbines in the form of a decreased efficiency are not taken into account. For small deviations from design load conditions, the error will be small. It becomes more important to consider the part-load decrease of efficiency when turbines are operated far from their design load. However, such operating modes are not found in the optimization here, although the simplification makes them more beneficial. Thus, the simplification is justifiable.

The modelling of cooling cost has also been subject to simplifications. Changes in operating costs for cooling water are neglected since these are small compared to other costs and revenues. However, if the cooling demand increases, new cooling towers are needed, and their investment costs might not be negligible. The cooling demand at the mill may increase due to the production increase, or it may decrease due to the energy efficiency measures that are taken. This has not been modelled explicitly. Instead, the investment cost of new cooling towers has been added to the cost of the recovery boiler. It is assumed that if the recovery boiler is not upgraded, enough steam savings will be carried out to make lignin separation possible, thus the increase in cooling demand will also be avoided.

Finally, some assumptions have been made regarding the potential for district heating. District heating demand changes due to seasonal as well as daily variations. The district heating demand curve corresponds to the small district heating system used by Svensson, I.-L. et al. (2008c). The small district heating system was chosen because Jönsson et al. (2008) showed a larger potential for profitable excess heat cooperation between mills and energy companies in small district heating systems. The district heating load/supply curve is not modelled in detail. Instead, the following simplifications are made: The year is divided into 20 time periods with varying demand. A waste incineration plant with a capacity of $0.96 \mathrm{MW}$ is available for heat supply. Due to the excellent economy of such a plant (waste has a negative cost) it is assumed to be the base load in all time periods. If excess heat of $100^{\circ} \mathrm{C}$ is used for district heating it is not available for other purposes, even though it is only utilized partly for district heating. 
Technical data needed for calculating the output-to-steam ratio are summarized in Table 4 while Table 5 shows the properties of steam and water at the mill. The pulp mill is operated for about 7800 hours each year.

Table 4: Technical data used in the model.

\begin{tabular}{ll}
\hline Parameter & Value \\
\hline Turbine isentropic efficiency & \\
- New BP turbine & $85 \%$ \\
- Existing BP turbine & $80 \%$ \\
- Condensing turbine & $81 \%$ \\
Turbine mechanical efficiency & \\
- BP turbine & $95 \%$ \\
- Condensing turbine & $95 \%$ \\
Heating value of lignin & $24.1 \mathrm{MJ} / \mathrm{kg}$ \\
Recovery boiler efficiency & $92 \%$ \\
Medium quality $\left(100^{\circ} \mathrm{C}\right)$ excess heat available for district heating & $16.3 \mathrm{MW}$ \\
Low quality $\left(60^{\circ} \mathrm{C}\right)$ excess heat available for heat pumping & $53.8 \mathrm{MW}$ \\
Heat pump COP (heat output / elec. input) & 2.8 \\
\hline
\end{tabular}

Table 5: Steam and water properties at the mill.

\begin{tabular}{lll}
\hline Steam/water & $\begin{array}{l}\text { Pressure } \\
\text { [bar] }\end{array}$ & $\begin{array}{l}\text { Temp } \\
{\left[{ }^{\circ} \mathbf{C}\right]}\end{array}$ \\
\hline HP steam & 60 & 450 \\
MP steam & 11 & 200 \\
LP steam & 4.5 & 150 \\
Feed water & & 120 \\
Returning condensate & & 100 \\
Cond. turbine condenser & & 35 \\
Quench water & & 18 \\
\hline
\end{tabular}

From the data given in Tables 4 and 5, the conversion from steam to electricity, lignin, or district heating can be calculated, as well as the conversion between different steam pressure levels and other necessary energy balance parameters. Under certain circumstances, it is possible to increase the output without using any extra steam. This is the case for the new back-pressure turbine for which the output is increased compared to the old one, simply because it has a higher efficiency. This is also true for district heating supplied by excess heat and not by steam.

Figure 4 illustrates the demand for district heating under the assumption that the base load is supplied from waste heat. Using excess heat from the mill is the next cheapest production alternative. 


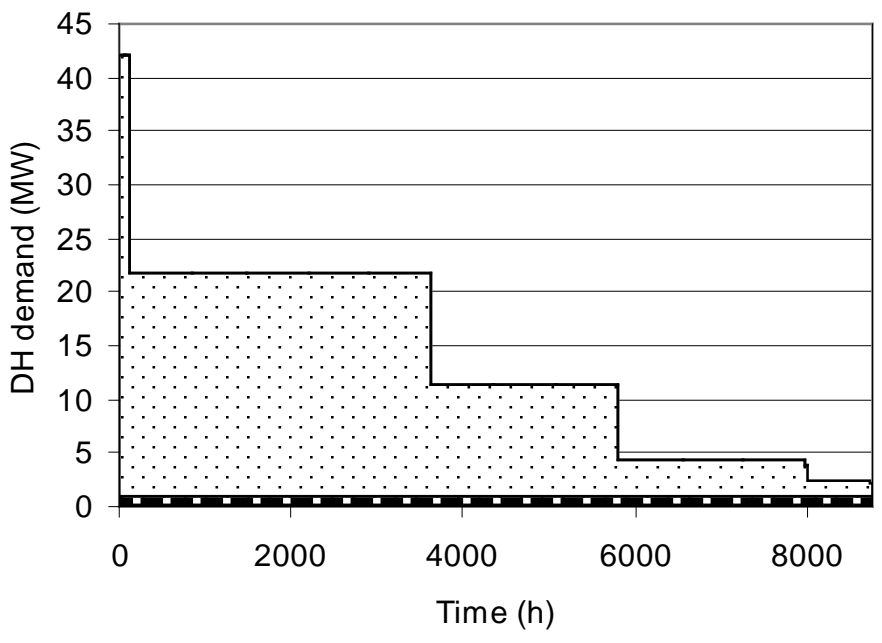

Waste incineration plant $\square$ Other production alternatives

Figure 4: Demand curve for district heating showing the possible use of excess heat from the mill for district heating.

Investment costs for process equipment are generally given by nonlinear concave functions. A piecewise linearization of the investment costs is carried out by an AMPL (Fourer et al., 2003) script. An absolute error tolerance of $0.05 \mathrm{M} €$ and a relative error tolerance of $3 \%$ were used for the difference between the piecewise linear approximation and the original function. The investment costs are assumed to be expressed as

$$
\text { cost }=a(\text { installed capacity }+c)^{b} \text {, }
$$

where the values of the parameters $a, b$, and $c$ are given in Table 6 . The number of linearization intervals is eight for the condensing turbine and ten for the back-pressure turbine and the lignin separation plant, respectively. For the three district heating measures, the original investment cost functions are already linear and hence, naturally, a single interval is sufficient.

District heating additionally requires investing in piping between the mill and the district heating system. The investment cost is split between the energy company and the mill. It is modelled as a fixed cost measure with zero steam savings. The investment is required to be made when any of the district heating measures are chosen. The part of the cost for district heating piping paid for by the mill is 6.6 M€, corresponding to half of the cost assumed by Svensson, I.-L. et al. (2008c).

Table 6: Parameters used in the investment cost function: cost $=a$ (installed capacity $+c)^{b}$.

\begin{tabular}{llll}
\hline Energy export measure & $\boldsymbol{a}[\mathbf{M} \boldsymbol{}]$ & $\boldsymbol{b}$ & $\boldsymbol{c}$ [MW] \\
\hline Lignin & 0.882 & 0.6 & 0 \\
BP turb & 1.09 & 0.6 & 0 \\
Cond. turb & 1.96 & 0.6 & 0 \\
DH LP & 0.03 & 1 & 19 \\
DH 100 & 0.4 & 0 & 0 \\
DH 60 & 0.109 & 1 & 0 \\
\hline
\end{tabular}


Reinvestments in already implemented technologies are possible. The investment costs for such additions of capacity follow the same cost functions as new investments. This means that the cost for added capacity is the same as the cost for a new unit of the same size as the increase. An additional requirement is that the first new back-pressure turbine always has to fully replace the existing turbine, which has a capacity of $24.7 \mathrm{MW}$. It could also, theoretically, be of interest to invest in a smaller turbine in order to be able to change the steam flow distribution through the turbine (see Section 3.3). The cost for such an upgrade is underestimated in this model, since it is sufficient to increase the capacity by a minimum, in order to deactivate the governing constraint. The results from the optimization show, however, that this investment will not be of interest although the cost is underestimated, and hence, there is no need to improve the modelling for this case study.

The operating cost of lignin extraction consists of costs for chemicals and extra electricity. The operating cost is thus a function of the electricity price. This is also the case for the heat pump, for which the operating cost is made up of the cost for the supplied electricity. Table 7 shows the operating cost functions for the lignin extraction and the heat pump. For the other measures there is no operating cost. Maintenance costs have been neglected.

Table 7: Operating cost functions.

\begin{tabular}{ll}
\hline & Operating cost [€/MWh output] \\
\hline Lignin separation plant & $5.72+0.0162$ elec. price \\
Heat pump (DH 60) & elec. price / 2.8 \\
\hline
\end{tabular}

The economic parameters used are the discount rate and the economic lifetime of the investments. These are parameters that the decision-maker is free to choose. For a strategic view a long lifetime and a low discount rate should be chosen. For a more shortterm perspective one should choose a short lifetime and a high discount rate, see also Svensson, E. et al. (2008b) for more discussions on the economic parameters. The purpose of this paper is not to discuss different choices of these parameters; they should be chosen by the decision-makers at the mill facing the upcoming investment.

\subsection{Step 4 - Develop a scenario model}

The starting point for modelling uncertainty is a model for generating energy market scenarios (Axelsson et al., 2007). By the use of this model, three scenario blocks are generated. One scenario block representing present Swedish conditions is then added. The four blocks are described below.

Block I. The Swedish energy market in the near future. Electricity and biofuel prices as well as marginal power production technology and policy instrument conditions are based on data from the first quarter of 2006.

Block II. A 'business as usual' evolution of society. Block II replaces Block I after the year 2015 in scenarios without increased prices of $\mathrm{CO}_{2}$ emission permits. Swedish electricity prices are by then assumed to be set by the marginal European electricity price. 
Block III. A 'moderate change' evolution of society. The price of $\mathrm{CO}_{2}$ emission permits is increased compared to the present value (corresponding to an assumed decrease on the $\mathrm{CO}_{2}$ emissions cap). The green power certificates are, however, assumed to drop in price because of the higher $\mathrm{CO}_{2}$ charge, which also promotes green electricity production.

Block IV. A 'sustainable' evolution of society, i.e. the price of $\mathrm{CO}_{2}$ emission permits is further increased compared to Block III. Consequently, the green power certificates are further reduced in price as well.

Since all energy at the pulp mill is based on biomass from the wood raw-material, the trading with $\mathrm{CO}_{2}$ emission permits will not directly influence the economy of the mill. An increased price of emission permits will, however, affect the electricity and the biofuel prices, and thereby also the cost-effectiveness of energy efficiency investments at the mill.

The inputs to the energy market scenario tool developed by Axelsson et al. (2007) are fossil fuel prices (without taxes, etc.), $\mathrm{CO}_{2}$ emissions charges (in the form of a tax, or as in this case, a price of emission permits), green electricity certificates, and possibly green transportation fuel certificates. The tool is used to generate prices for electricity and forest by-products. Here, the lignin price is assumed to be $50 \%$ higher than the price for byproducts. There is no market price for lignin at the moment, but there are ongoing discussions about how it should be valued. Axelsson and Berntsson (2008) assume that the price will be $35 \%$ higher than for by-products. Here, a slightly higher value is deliberately chosen, partly in order to obtain a case study that will clearly illustrate our methodology. Heat price is set to $75 \%$ of the cost of the alternative production of heat, which in this study is assumed to be a biofuel boiler. The electricity generated at the pulp mill is granted electricity certificates since it is produced from biofuel. The parameter sets used in the scenario building blocks are presented in Table 8.

Table 8: Parameter sets for the four scenario building blocks.

\begin{tabular}{lcccc}
\hline & \multicolumn{4}{c}{ Scenario block } \\
Price parameters [€/MWh] & I & II & III & IV \\
\hline Electricity price & 38.6 & 57.3 & 60.8 & 61.9 \\
Green electricity certificates & 21.7 & 16.0 & 10.6 & 5.3 \\
Lignin price & 19.5 & 22.9 & 26.9 & 31.0 \\
District heating price & 21.3 & 25.3 & 29.5 & 33.7 \\
\hline
\end{tabular}

Based on the four blocks described above a number of possible development paths are constructed in accordance with the methodology described by Ådahl and Harvey (2007). The building blocks are assumed to be valid for five-year intervals, and the development paths range over 30 years, enabling the analysis of investments with an economic lifetime of up to that length. The development paths are illustrated in Figure 5. 


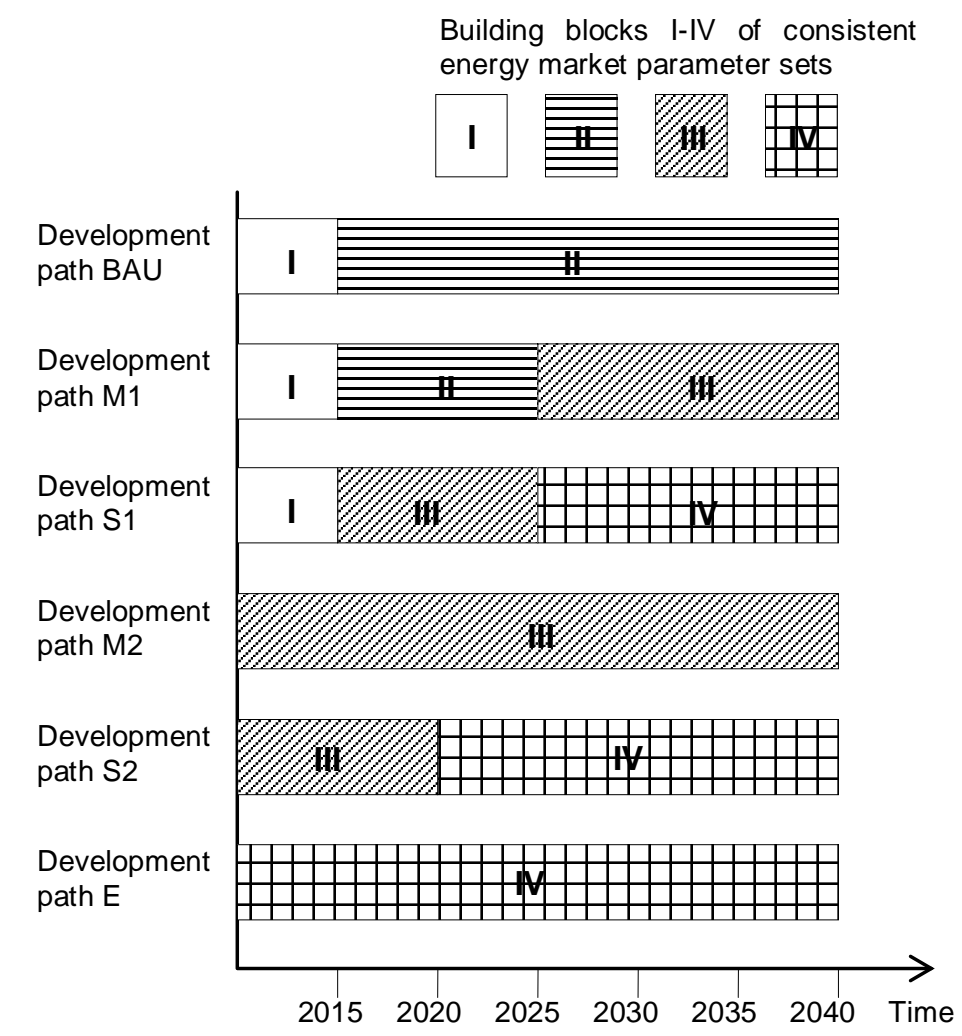

Figure 5: Development paths for energy market parameters.

BAU denotes a 'business as usual' development, with minor attention to climate issues. M1 denotes a moderate climate concern in the distant future while M2 denotes a moderate concern in the near future. S1 and S2 describe a development towards sustainability in the distant and the near future respectively. Finally path E denotes an extreme development towards sustainability where a radical change happens in the very near future.

The development paths can also be illustrated as a scenario tree (see Figure 6), consistent with the usual description of discrete probability distributions in the field of stochastic programming (Birge and Louveaux, 1997; Ruszczyński and Shapiro, 2003). The probabilities for the nodes in the scenario tree can easily be calculated when the probabilities for each of the development paths are given. These probabilities are of course not known, but can be assumed and easily changed to test different properties of the probability function. 


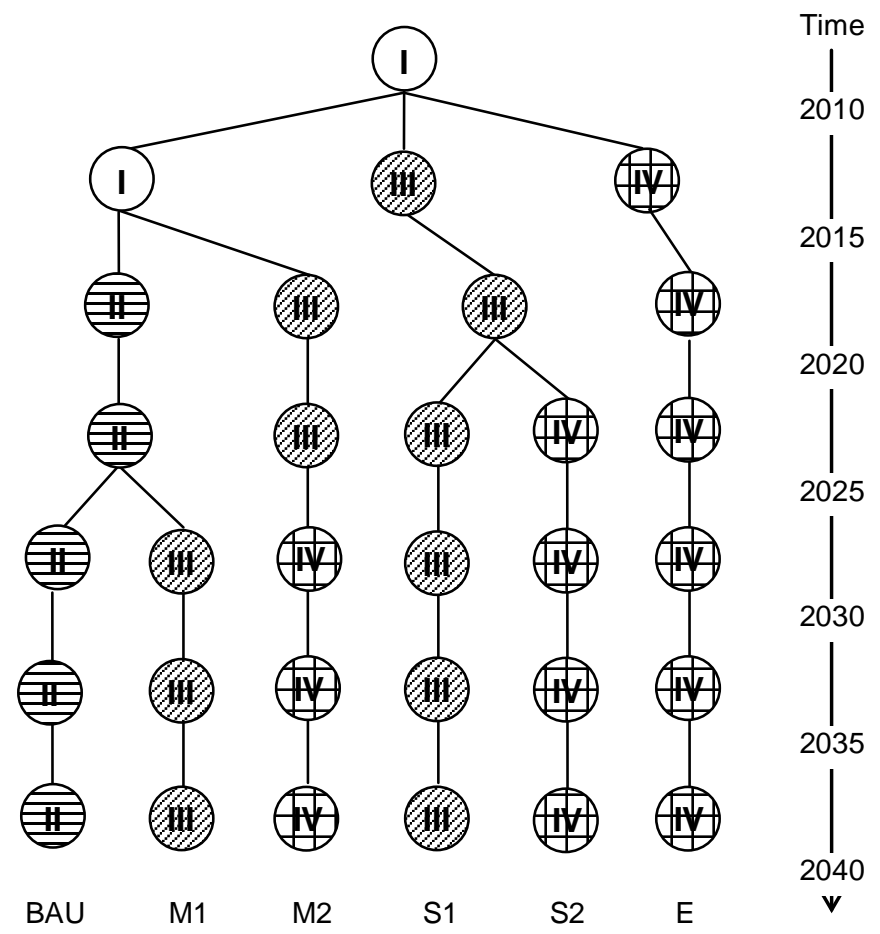

Figure 6: Scenario tree for the stochastic model.

\subsection{Step 5 - Solve the model and analyze the results}

The model was implemented in the mathematical modelling language AMPL (Fourer et al., 2003) and solved with the general purpose integer linear programming solver CPLEX (ILOG, 2006). The results are presented in Section 4. The objective function, as expressed below, is to maximize the expected net present value (NPV) of the investments:

$$
\text { maximize } \mathrm{E}[\mathrm{NPV}(x)]:=-C_{0}\left(x_{0}\right)+\sum_{s \in S} p_{s} \sum_{t=1}^{T} \frac{C_{t}\left(x_{0}, x_{s}, \omega_{s}\right)}{(1+r)^{t}} \text {, }
$$

where $\mathrm{E}$ denotes expectation, $S$ denotes the set of all scenarios (or paths) $s, p_{s}$ is the probability for scenario $s$ to occur, $x=\left(x_{0}, x_{s}\right)$ where $x_{s}$ is a vector of decision variables corresponding to scenario $s$, representing investment decisions and decisions on steam use, and $x_{0}$ is the vector of decision variables associated to the initial investment and which is independent of $s$. Further, the initial investment $C_{0}$ is a piecewise linear function of the decision variables, $x_{0}$, and the net cash flow $C_{t}$, in year $t$, is a function of the investment and load decisions, $x_{s}$ and $x_{0}$, and the uncertainty parameters (electricity, lignin and heat prices), $\omega_{s}$, for scenario $s$. Finally, $T$ is the economic lifetime (in years) of investments and $r$ is the discount rate. The net cash flow of the final year, $C_{T}$, is adjusted for value remaining after the economic lifetime (the residual value).

\section{Results}

We next present results from the case study presented in Section 3. 


\subsection{Main results}

In the first run, a strategic view on investments is employed. Such strategic views are becoming more common as a consequence of rising energy prices and uncertainties about future climate policies, and with a long-term perspective the kind of methodology presented in this article becomes more meaningful. Within the industrial R\&D programme FRAM (FRAM, 2005), an annuity factor of 0.1 has been identified as reasonable for strategic decisions. This corresponds to a discount rate of $9 \%$ when the calculation horizon is set to 30 years.

A discount rate of $9 \%$ is quite high, at least compared to a risk-free rate. However, since we intend to analyze a period of 30 years, $9 \%$ is the discount rate required to obtain the recommended annuity factor of 0.1. Additionally, although uncertainties in the future energy market is accounted for explicitly, there are other uncertain parameters, for example such related to technical risk, that motivates the use of a higher discount rate.

The model for maximization of the expected net present value (NPV) of the investments was solved for five slightly different probability distributions which are presented in Table 9. The first distribution has a high probability for a 'business-as-usual' development (with slow and moderate changes) while the second distribution represents a higher probability for fast substantial changes. The third distribution is almost uniform, with equal probabilities for the different paths. Distributions four and five are also rather 'nice', with low probabilities for the two extremes, BAU and E. Distribution four represents higher probabilities for changes occurring in the distant future, while distribution five represents higher probabilities for a development towards sustainability.

Table 9: Path probabilities for five different distributions.

\begin{tabular}{l|ccccc}
\hline & $\mathbf{1}$ & $\mathbf{2}$ & $\mathbf{3}$ & $\mathbf{4}$ & $\mathbf{5}$ \\
\hline BAU & 0.25 & 0.05 & 0.16 & 0.05 & 0.05 \\
M1 & 0.25 & 0.10 & 0.17 & 0.30 & 0.15 \\
M2 & 0.20 & 0.15 & 0.17 & 0.15 & 0.15 \\
S1 & 0.15 & 0.20 & 0.17 & 0.30 & 0.30 \\
S2 & 0.10 & 0.25 & 0.17 & 0.15 & 0.30 \\
E & 0.05 & 0.25 & 0.16 & 0.05 & 0.05 \\
\hline
\end{tabular}

The model was also solved for each of the six distributions with probability 1 for one of the paths and probability 0 for the others. Optimizing for one path at a time is essentially the same as doing a sensitivity analysis. The solution value for the realized paths, i.e. the paths that turn out to be the true development, is shown in Figure 7. The leftmost group of bars (four bars with light-grey patterns and one black bar) illustrates what will be the resulting NPV from the different distributions if reality turns out to follow a BAU scenario. The next group of bars illustrates different solutions when M1 is the realized path, and so on. 


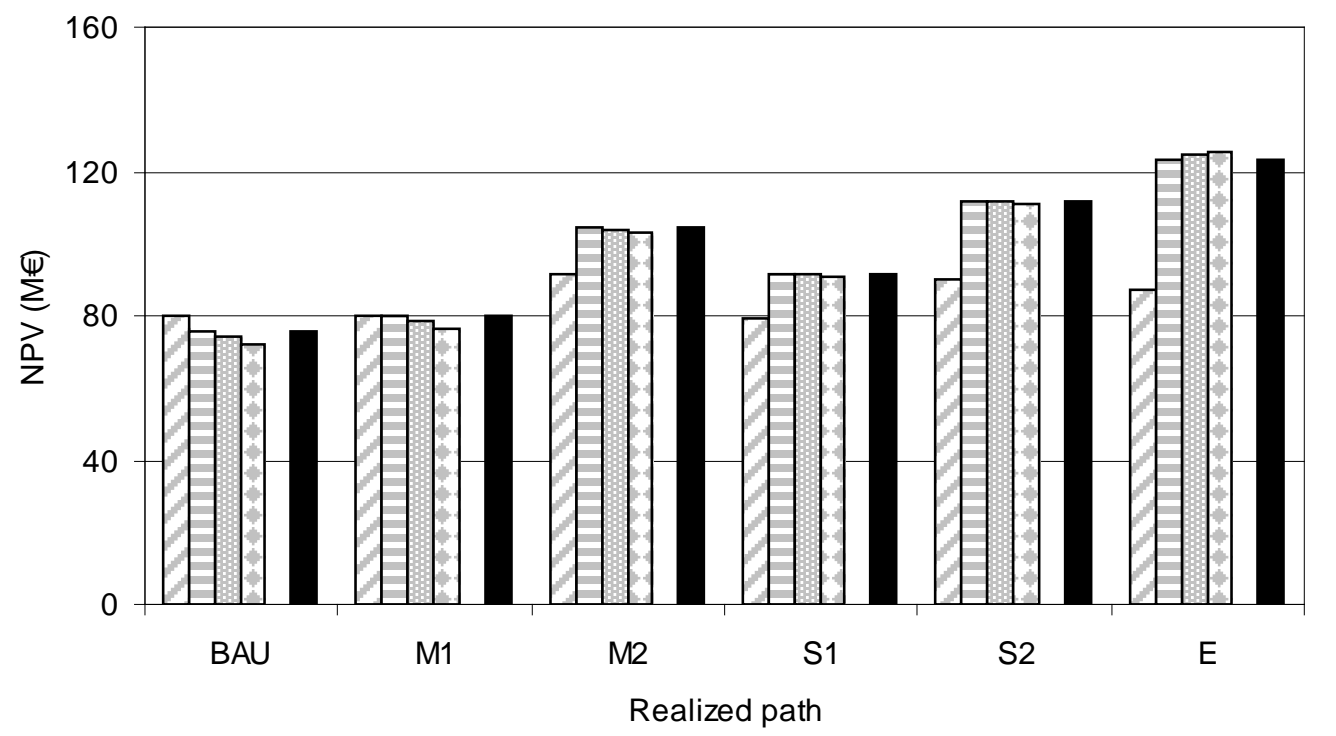

Optimized for path BAU or M1

Optimized for path M2 or S1

Optimized for path S2

Optimized for path E

Optimized for any of the probability distributions 1-5

Figure 7: NPV for the realized path when investments are optimized for either: $a$ single path (light-grey patterns) or a probability distribution of paths (black). Lifetime $=30$ years, discount rate $=9 \%$.

The light-grey patterned bars show the solution value - the NPV of the investments when investments are optimized for a single path, which corresponds to setting the probability to 1 for that path and 0 for all the others. The patterned bars thus illustrate what could have been achieved with a sensitivity analysis.

The black bars show the solution value when the probability distributions given in Table 9 are used. Note that all of the probability distributions 1-5 yield the same solution value. Note also that this actually seems to be the best solution overall. Another important reflection is that the solution obtained by the stochastic optimization (using the probability distributions from Table 9), is always better than the worst solution obtained by the path-wise optimization.

The results show a bigger difference between NPV for different realizations, than between different solution values for one specific realization (calculated as a standard deviation of the average values). This should be an interesting finding for policy-makers, implying that a change in policies aiming at a more sustainable development increases the profitability of all energy efficiency measures, but to a lesser extent influences what types of such investments are optimal.

For none of the solutions obtained by varying the probabilities for the scenarios reinvestments occur, even though such are possible in the model. All investments are thus made initially. This shows that later investments are not profitable, even though they could be a way to improve the situation in a realized scenario when an initial decision was 
made which was not optimal for that scenario. Steam savings are made to a comparable extent for all solutions considered. There are, however, differences in how the steam is used. Three main alternatives arise for the initial investment. These are presented in Table 10.

Table 10: Main alternatives for initial investments.

\begin{tabular}{l|l}
\hline Investment alternative & Description \\
\hline RBU + turbines & $\begin{array}{l}\text { Investment in a recovery boiler upgrade (RBU) and use } \\
\text { of steam savings for electricity generation and district } \\
\text { heating. The optimal solution for paths BAU and M1. } \\
\text { Avoid RBU and maximize the lignin extraction. The } \\
\text { optimal solution for path E. Lower temperature excess } \\
\text { heat is used for district heating. } \\
\text { Eust enough lignin }\end{array}$ \\
$\begin{array}{l}\text { Extract just enough lignin to avoid the RBU investment. } \\
\text { Use the rest of the steam surplus for electricity generation } \\
\text { and for district heating. The optimal solution for all of the } \\
\text { probability distributions 1-5 as well as for paths M2, S1. } \\
\text { A very similar solution, with a little more lignin } \\
\text { extraction and a little less electricity production is the } \\
\text { optimal solution for path S2. }\end{array}$ \\
\hline
\end{tabular}

The capacities for electricity generation, district heating deliveries, and lignin exports are shown in Figure 8. It is interesting that the optimal solution is a combination of the two extremes: maximum lignin separation and maximum electricity generation, respectively. Our results show the importance of including also the possibility for such combinations in the investment analyses.

A number of reflections regarding the methodology can be made based on these results. It is obvious that a decision based entirely on a business-as-usual scenario might be a rather poor one. It is also clear that just exchanging the business-as-usual scenario for another development path is not the right thing to do if it is not known which path is going to be realized. With the use of the methodology described in this paper, a more robust solution, i.e. a solution that is good for a variety of scenarios, can be achieved.

There are of course other applications where changes in the probability distribution may lead to changes in the solution obtained. The methodology proposed here would still make the estimation about the future an easier task since it does not require information about which will be the true development path, but rather what the probabilities for the different scenarios are. For this case study, it is possible to show that the solution to the stochastic program is robust, in the sense that the same investment decisions are optimal for reasonable variations in the probability distribution. Hence, not only for uncertain parameters under a known probability distribution, but also when the probability distribution is hard to estimate, it will be possible to identify a robust solution. 


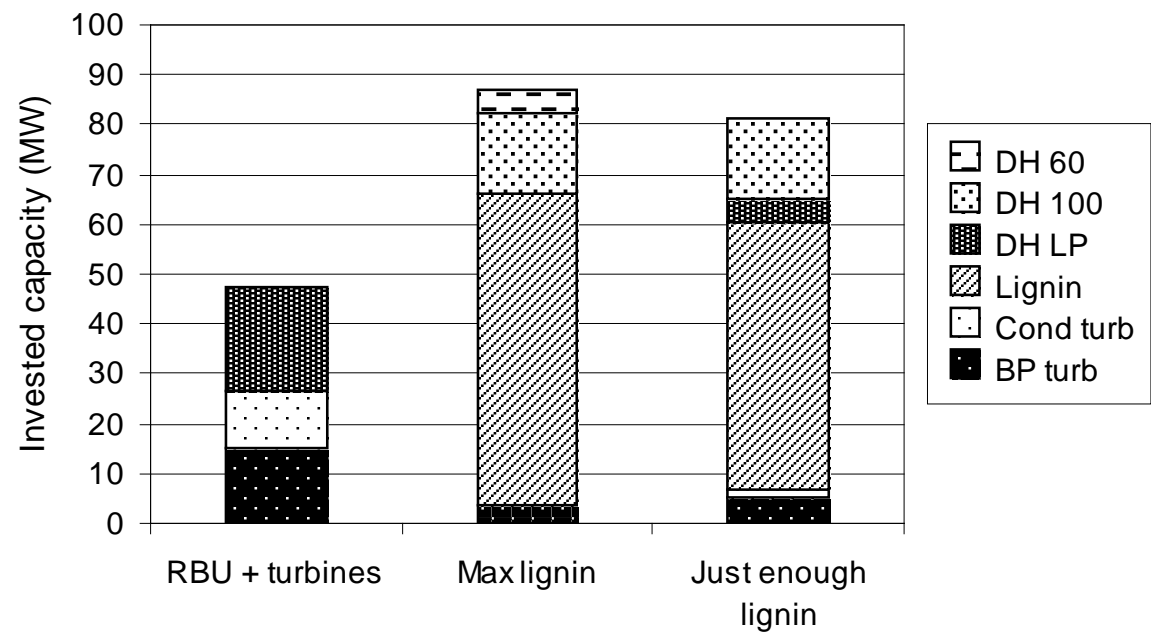

Figure 8: The main investment alternatives and their characteristics, see also Table 3. Invested capacity refers to capacity exceeding the existing capacity of the mill.

\subsection{Strategic or short-term perspective? - Varying the values of the economic parameters}

In order to demonstrate how the choice of the economic parameters affects the solution, the economic lifetime and the discount rate were changed and the optimization resolved. The analyzed time horizon was changed according to the economic lifetime. The parameters were changed such that the annuity factor was kept at either 0.1 (a strategic view) or 0.2 (a more short-term perspective). Table 11 shows the three combinations of the economic parameters that were tested in addition to the one already presented. Especially for the annuity factor of 0.2 , the discount rates used are high, which should imply that the future price levels will not affect the decisions as much.

Table 11: Combinations of economic parameters tested.

\begin{tabular}{lrl}
\hline Lifetime & $\begin{array}{l}\text { Discount } \\
\text { rate }\end{array}$ & $\begin{array}{l}\text { Annuity } \\
\text { factor }\end{array}$ \\
\hline 30 years & $9 \%$ & 0.1 \\
15 years & $6 \%$ & 0.1 \\
30 years & $20 \%$ & 0.2 \\
15 years & $18 \%$ & 0.2 \\
\hline
\end{tabular}

Our tests show that, as long as the annuity factor was kept constant, the solutions possessed the same characteristics regarding the solutions for the five probability distributions. Also for five of the six single path solutions the solution remains the same as long as the annuity factor is kept constant. The exception is path S2, where a change in solution, although minor, occurs when $\mathrm{T}$ is changed from 30 to 15 years, resulting in that the same solution is optimal for path S2 as for paths M2 and S1. The knowledge that the solution is primarily dependent on the annuity factor (not as much on economic lifetime and discount rate) should definitely facilitate the investment decision in this case study, because it is sufficient to choose an appropriate annuity factor, while the choice of economic lifetime and discount rate is less important. However, this situation will 
probably not hold for other applications in which the opportunity to wait is a more realistic alternative.

The main results for the two different values of the annuity factor are presented in Table 12. The optimal initial investment refers to the three main investment alternatives, which are described in Table 10 and illustrated in Figure 8, but another solution that is obtained for the short-term view optimizations is also introduced and denoted by 'Shortterm'. Except for some differences due to less investments in steam savings and condensing turbine with the higher annuity factor, the 'Short-term' solution have, however, the same characteristics as that of the 'Just enough lignin' solution.

Table 12: Optimal solution dependence on the annuity factor.

\begin{tabular}{lllll}
\hline \multirow{2}{*}{$\begin{array}{l}\text { Annuity } \\
\text { factor }\end{array}$} & \multicolumn{2}{l}{ Results for prob. distr. 1-5 } & \multicolumn{2}{l}{ Results for path solutions } \\
\cline { 2 - 5 } & Distr. & Optimal initial & Path with & Optimal initial \\
\hline 0.1 & No & investment & probability $=1$ & investment \\
& & Just enough lignin & BAU/M1: & RBU + turbines \\
& & & M2/S1: & Just enough lignin \\
& & & S2: & Just enough lignin \\
& & & E: & Max lignin \\
\hline 0.2 & $1-5:$ & Short-term $^{\mathrm{b}}$ & M2/S1/S2/E: & Short-term \\
& & & BAU/M1: & Short-term \\
\hline
\end{tabular}

${ }^{\mathrm{a}}$ With $\mathrm{T}=15$ years and $\mathrm{r}=6 \%$, exactly the 'Just enough lignin solution' presented in Figure 8. With $\mathrm{T}=30$ years and $\mathrm{r}=9 \%$, more of the blocks IV in path S2 are accounted for and hence a little more lignin and a little less electricity.

${ }^{\mathrm{b}}$ Just enough lignin is extracted to avoid RBU. Due to a high annuity factor, no investment is made in a condensing turbine, less steam savings are carried out, the back-pressure turbine is smaller and DH 60 replaces DH LP.

' A variation of the 'Short-term' solution described above where neither DH LP nor DH 60 are carried out $(<0.2 \%$ difference in NPV).

As can be seen, the 'Just enough lignin' alternative turns out to be a robust solution when the annuity factor is 0.1 . Also for an annuity factor of 0.2 , corresponding to a short-term perspective, a variation of the 'Just enough lignin' is the optimal solution for all probability distributions. When the annuity factor is 0.2 , the same solution is the optimal one for all paths but BAU and M1, where the solution, however, is similar and yields almost exactly the same solution values. The reason for the larger variations when the annuity factor is 0.1 is that differences in future price levels have a stronger influence on strategic decisions. Overall, the results confirm that the importance of incorporating these kinds of uncertainties in the investment optimization becomes more pronounced when making strategic decisions.

Finally, we compare the results presented so far with those obtained from a traditional, deterministic investment analysis, using the present value of all price parameters throughout. This corresponds to a single development path of scenario block I. With an annuity factor of 0.2 , the solution actually becomes the 'Just enough lignin' solution that was achieved in the stochastic optimization using the same annuity factor. With an annuity factor of 0.1, which would imply the intent to make a more strategic decision, however, the solution is given by the 'RBU + turbines' alternative. This is an expected but important finding since it means that with a more long-term perspective it is increasingly important to actually perform the analysis as proposed in this paper. When 
striving for a strategic investment plan, uncertainties and expected changes in the future scenario must be accounted for in order to achieve a robust, well-founded solution.

\subsection{Model validation for a larger set of scenarios}

A scenario tree built from the same parameter blocks as in the original case, but with twice as many branches, was used for validation of the model. These runs (with an annuity factor of 0.1 ) resulted in the same optimal solutions as the ones previously presented. For this case study, it is thus shown that the optimal solution is not sensitive to the size of the scenario tree in itself.

\subsection{The value of the stochastic solution and the expected value of perfect information}

In order to analyze the advantages of incorporating uncertainties in an optimization model assuming a known probability distribution, the usual procedure is to compare the expected objective value of the stochastic model with that obtained by using the mean values of the uncertain parameters in a deterministic model. The obtained result is called the value of the stochastic solution (VSS). In order to analyze the reward for resolving uncertainty, the expected value of perfect information (EVPI) is calculated, which is a measure of what could be achieved if all future parameters were known for certain. For a detailed explanation of these measures as well as the basic theory of stochastic programming, the reader is referred to a standard textbook on the subject, see e.g. Birge and Louveaux (1997). It should be noted that the VSS and the EVPI measures were developed for stochastic models for which the probability distribution is known. Under the assumption of one specific probability distribution, the VSS and EVPI can be calculated from three other measures:

- Wait-and-see (WS), the objective value of the stochastic model assuming perfect information, i.e., that all uncertainty is resolved before any decision is made. This value corresponds to the weighted sum of the optimal solution values for each path presented in Figure 5, where the weights are the path probabilities. For each path, the path-optimal solution value is shown in Figure 7.

- Here-and-now (HN), the objective value of the stochastic model assuming that decisions must be made before uncertainties are resolved. This is the solution to the optimization model in Eq. (1). In Figure 7, this value corresponds to the weighted sum of the solution values illustrated by black bars for the probability distribution assumed. Again, the weights are the probabilities.

- Expectation of mean value (EMV), the objective value of the stochastic model using investment decisions from a model where the random energy prices are replaced by their respective expectations.

VSS and EVPI can then be expressed as: VSS $=\mathrm{HN}-\mathrm{EMV}$ and EVPI $=\mathrm{WS}-\mathrm{HN}$.

For this case study, however, the value of VSS turns out to be zero for all of the probability distributions considered. This means that the value of the 'here-and-now' solution equals the value of the 'expectation of mean value' solution. A closer analysis shows that not only the solution values, but also the solutions are in fact the same. This result implies that the solution, which we found to be optimal could have been obtained simply by optimizing the investment using the mean values of the parameters. This is, however, not a general result, and it could not have been assumed without actually 
carrying out the calculations. Moreover, in practice the procedure is typically not to optimize the investment for the mean value, but rather to optimize it for different single scenarios, picking a solution that 'seems' to behave well overall. The methodology proposed here, including the principles for analyzing solutions, provides a suggestion for a more explicit analysis of whether a solution 'seems' good.

An explanation to that VSS here becomes zero is that although there are many investment alternatives including all the steam savings, there are actually very few main investment alternatives (see Table 10), out of which two can, to some extent, be regarded as extremes while the third one is really the middle-way solution. Furthermore, the opportunity to wait hardly exists in this case, because of the planned production increase which makes immediate investments a necessity.

The calculation of EVPI results in values ranging from 0.4 M€ to 1.3 M€ for the five probability distributions. This is actually not very much compared to the solution values (the NPV for the investments) which range from $76 \mathrm{M} €$ to $123 \mathrm{M} €$. Consequently, although the NPV can be increased by resolving the uncertainties, the increase is minor compared to what can be gained from actually going through with the investments in spite of the uncertainties.

\section{Further work}

An article presenting a detailed description of the optimization model is currently being written, in which we carry out additional analyses; some ideas are briefly discussed here. In this paper, we have shown that a reasonable change of the probability distribution will not alter the optimal solution. We intend to further analyze this property and investigate the limits for when the solution changes. Another extension is to include additional development paths. Other opportunities include analysis of the reasons for and consequences of the fact that VSS $=0$.

The reductions of $\mathrm{CO}_{2}$ emissions related to the energy efficiency investments have not been considered in this case study. Since the energy used at the mill is supplied from biomass, no on-site emissions reductions are achieved through improved energy efficiency. Reductions are, however, made possible off-site, for example by the production of electricity that can replace electricity produced in a coal power condensing plant. An important extension to the case study presented here is to carry out further work concerning the trade-off between minimizing $\mathrm{CO}_{2}$ emissions and maximizing NPV in a multiple objective optimization framework.

\section{Conclusions}

The methodology presented in Svensson, E. et al. (2008b) for making investment decisions in energy efficiency measures under uncertainty has been used in a case study.

It has been shown that an ordinary straightforward investment optimization where the parameters are constant over time might not result in the best solution, especially in a strategic perspective. The proposed methodology provides not only a way to account for the time dependence and the uncertainties of the parameters, but also a way to investigate how a solution is affected by changing the view from a short-term perspective to a longterm perspective.

Another conclusion is that it is important to compare not only opposing investment strategies, but also clever combinations of them. By using the proposed methodology all 
possible combinations can emerge as a natural consequence of using an optimization approach.

For the case studied, there is no profitability of reinvestments after the initial investments have been made, not even if the initial investment is optimized for one scenario but another scenario is realized.

An interesting finding in this case study is that the probability distribution of the scenario paths may be changed within reasonable limits without altering the optimal solution; this implies robustness of the identified solution and of the optimization model. In other words, the solution is not very sensitive to variations in the probability distribution. This result inspires us to further investigate the use of the proposed methodology for other applications as, for example, other types of industries.

Finally, the objective value differs notably for realizations of different development paths. For most paths, the difference between solutions or decisions is not that pronounced. This implies that policies with a high cost for emitting $\mathrm{CO}_{2}$ do not necessarily lead to a shift of decisions, but rather increase the net present value for all energy efficiency investments.

\section{Acknowledgements}

We kindly thank Prof. Michael Patriksson for his valuable contribution to this work. The Swedish Energy Agency is acknowledged for financing the project.

\section{References}

Axelsson, E., Olsson, M., Berntsson, T., 2006a. Heat integration opportunities in average Scandinavian kraft pulp mills: Pinch analyses of model mills. Nordic Pulp and Paper Research Journal, 21, 466-475.

Axelsson, E., Olsson, M., Berntsson, T., 2006b. Increased capacity in kraft pulp mills: Lignin separation and reduced steam demand compared with recovery boiler upgrade. Nordic Pulp and Paper Research Journal, 21, 485-492-

Axelsson, E., Harvey, S., Berntsson, T., 2007. A tool for creating energy market scenarios for evaluation of investments in energy intensive industry, in: Mirandola, A., Arnas, Ö., Lazzaretto, A. (Eds.), Proceedings of the 20th International Conference on Efficiency, Cost, Optimization, Simulation and Environmental Impact of Energy Systems, Padova, Italy, 2007, pp. 1587-1594.

Axelsson, E., Berntsson, T., 2008. Profitability and off-site CO2-emission reduction from energy savings in the pulp and paper industry in different future energy markets. Submitted for publication.

Birge, J.R., Louveaux, F., 1997. Introduction to Stochastic Programming. SpringerVerlag, New York.

Christiansen, D.S., Wallace, S.W., 1998. Option theory and modeling. Annals of Operations Research, 82, 59-82.

Fourer, R., Gay, D.M., Kernighan, B.W., 2003. AMPL: A Modeling Language for Mathematical Programming, 2nd Edition. Duxbury Press / Brooks/Cole-Thomson Learning, Pacific Grove, CA.

FRAM, 2005. FRAM Final report: Model mills. STFI, Stockholm, Sweden. 
Gielen, D., Taylor, M., 2007. Modelling industrial energy use: The IEAs energy technology perspectives. Energy Economics, 29, 889-912.

IEA, 2007. Tracking Industrial Energy Efficiency and $\mathrm{CO}_{2}$ Emissions. OECD/IEA, Paris, France.

ILOG, 2006. CPLEX: High-Performance Software for Mathematical Programming and Optimization, Ver. 10.1, http://www.ilog.com/products/cplex/

Jönsson, J., Svensson, I.-L., Berntsson, T., Moshfegh, B., 2008. Excess heat from kraft pulp mills: Trade-offs between internal and external use in the case of Sweden - Part 2: Results for future energy market scenarios. Energy Policy, doi:10.1016/j.enpol.2008.07.027.

Karlsson, M., Söderström, M., 2002. Sensitivity analysis of investments in the pulp and paper industry - On investments in the chemical recovery cycle at a board mill. International Journal of Energy Research, 26, 1253-1267

Karlsson, M., Sandberg, P., 2004. The MIND method: a decision support system based on MILP. Paper 8 in Sandberg, P., 2004. Optimisation and Co-operative Perspectives on Industrial Energy Systems. PhD Thesis, Division of Energy Systems, Department of Mechanical Engineering, Linköping University, Sweden.

Kemp, I.C., 2007. Pinch Analysis and Process Integration: A User Guide on Process Integration for the Efficient Use of Energy. Butterworth-Heinemann, Oxford.

Martin, N., Anglani, N., Einstein, D., Khrushch, M., Worrell, E., Price, L.K., 2000. Opportunities to improve energy efficiency and reduce greenhouse gas emissions in the U.S. pulp and paper industry. Lawrence Berkeley National Laboratory, report number LBNL-46141, Berkeley, CA.

Möllersten, K., Yan, J., Westermark, M., 2003. Potential and cost-effectiveness of $\mathrm{CO}_{2}$ reductions through energy measures in Swedish pulp and paper mills. Energy, 28, 691-710.

Olsson, M., Axelsson, E., Berntsson, T., 2006. Exporting lignin or power from heatintegrated kraft pulp mills: A techno-economic comparison using model mills. Nordic Pulp and Paper Research Journal, 21, 476-484.

Ruszczyński, A., Shapiro, A. (Eds.), 2003. Stochastic Programming, Vol. 10 of Lenstra, J.K., Nemhauser, G.L., Handbooks in Operations Research and Management Science. Elsevier, Amsterdam.

Smith, R., 1995. Chemical Process Design. McGraw-Hill, Inc, New York.

Svensson, E., Strömberg, A.-B., Patriksson, M., 2008a. A scenario-based stochastic programming model for the optimization of process integration opportunities in a pulp mill. Preprint ISSN 1652-9715, No 2008:29. Mathematical Sciences at Chalmers University of Technology and University of Gothenburg, Göteborg, Sweden.

Svensson, E., Berntsson, T., Strömberg, A.-B., Patriksson, M., 2008b. An optimization methodology for identifying robust process integration investments under uncertainty. Submitted to Energy Policy. 
Svensson, I.-L., Jönsson, J., Berntsson, T., Moshfegh, B., 2008. Excess heat from kraft pulp mills: Trade-offs between internal and external use in the case of Sweden - Part 1: Methodology. Energy Policy, doi:10.1016/j.enpol.2008.07.017.

Ådahl, A., Harvey, S., 2007. Energy efficiency investments in kraft pulp mills given uncertain climate policy. International Journal of Energy Research, 31, 486-505. 